\title{
Swiss Biodiversity Monitoring BDM (Z9 Plants)
}

\author{
Thomas Stalling
}

\begin{abstract}
Switzerland is one of the first countries in the world to monitor its biological diversity. The Federal Office for the environment (FOEN) has launched a programme for this purpose called Biodiversity Monitoring in Switzerland (BDM). In conjunction with the BDM programme, experts contracted by the Federal Government will regularly count animals and plants in numerous predetermined areas in the field. Whereas numerical qualitative objectives are accepted in most areas of environmental protection (emissions thresholds in air pollution control, for example), there are so far no targets for how biodiversity should change. Biodiversity monitoring helps us to define specific targets for nature conservation policy and to establish whether the measures that have been implemented are enabling us to reach these targets. Plants are surveyed for the state indicators Z7 (species diversity in landscapes) and Z9 (species diversity in habitats). This report describes the available content in the vegetation-plot database of the Swiss Biodiversity Monitoring BDM (Z9 Plants) (GIVD ID EU-CH-002).
\end{abstract}

Keywords: habitat; monitoring; surveillance; Switzerland; vegetation.

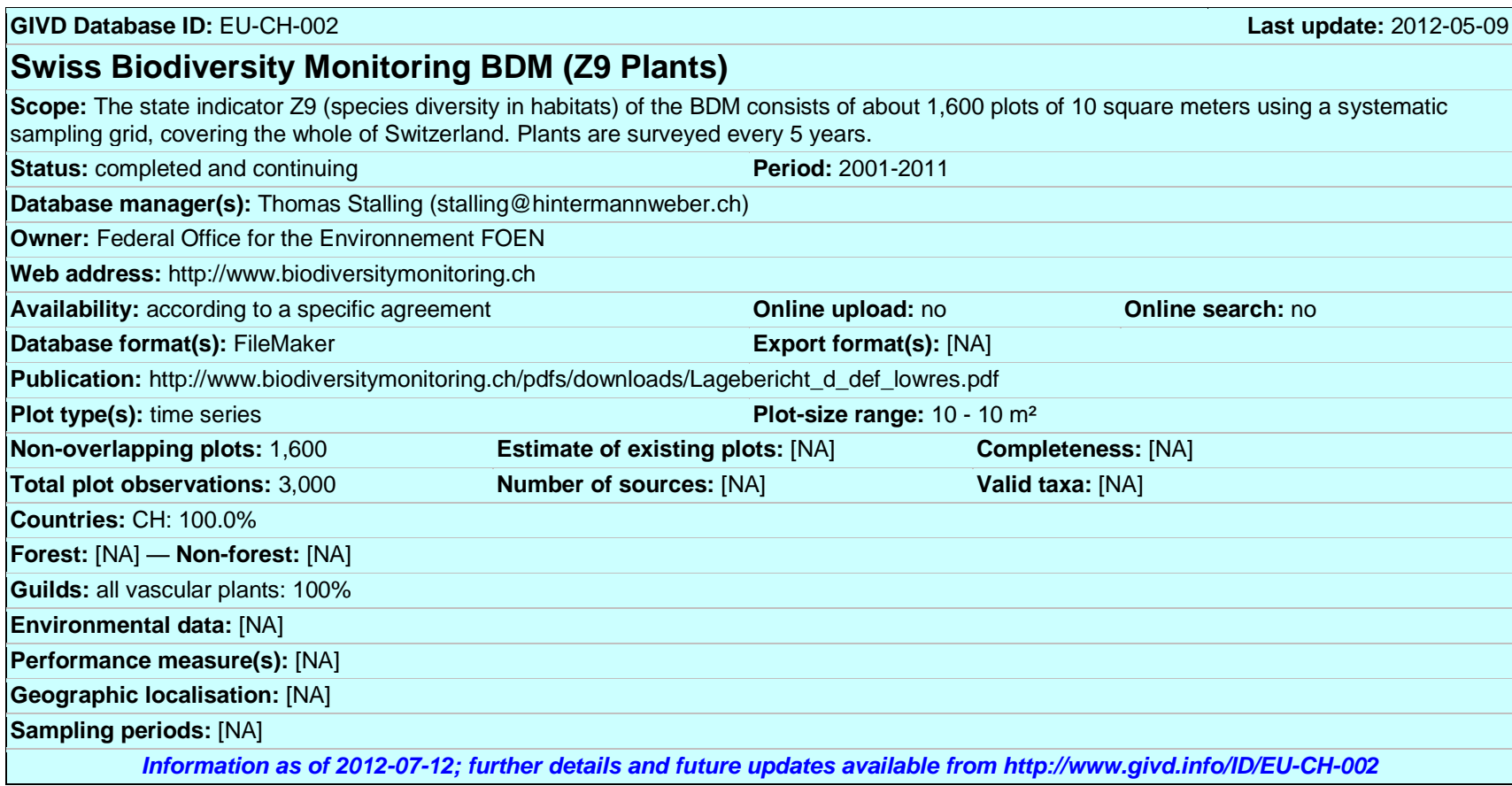

Thomas Stalling (stalling@hintermannweber.ch)

Hintermann und Weber AG, Au Str. 2a, 4153 Reinach BL, SWITZERLAND 